\title{
Haurdunaldiko kutsadura atmosferikoaren eta jaioberriaren tiroxina- mailaren arteko erlazioa, INMA-Gipuzkoa
}

\section{Relation between atmospheric pollution exposure while pregnant and thyroxin-level at birth, INMA-Gipuzkoa}

Arantxa Txintxurreta Agirre ${ }^{1}$, Aitana Lertxundi Manterola ${ }^{2,3,4}$, Amaia Irizar Loibide ${ }^{4}$, Maria Dolores Martínez López de Dicastillo ${ }^{4,5}$, Jesús Ibarlucea Maurulogoitia ${ }^{4,6}$

\author{
${ }^{1}$ EHUko Osasun Publikoko masterreko ikaslea \\ ${ }^{2}$ Prebentzio Medikuntza eta Osasun Publikoa Saila, UPV/EHU \\ ${ }^{3}$ CIBEResp, Centro de Investigacion Biomédica en Red, Madrid \\ ${ }^{4}$ BIODONOSTIA, Osasun Ikerketa Institutoa, Donostia \\ ${ }^{5}$ Eusko Jaurlaritza, Ingurumen Ikuskaritza Zerbitzua, Donostia \\ ${ }^{6}$ Osasun Publikoko Zuzendariordetza, Eusko Jaurlaritza
}

lastofardua@gmail.com

\section{Laburpena}

Kutsadura atmosferikoak tiroidean eragiten du, azken urteotako ikerketak agerian uzten ari direnez. Lan honetan aztertu nahi izan dugu jaioberriaren orpoko odolean neurtutako T4 hormona tiroideo totalean zer eragin ote duten jaio aurretiko $2.5 \mu \mathrm{m}$-ko edo gutxiagoko diametroko partikulekiko $\left(\mathrm{PM}_{2.5}\right)$ zein aireko nitrogeno dioxidoarekiko $\left(\mathrm{NO}_{2}\right)$ esposizioek. Aztertutako lagina Gipuzkoako INMA ikerketatik atera dugu. Elkarrekintza estimatzeko eredu lineal multibarianteak erabili ditugu. Zenbat eta handiagoa $\mathrm{PM}_{2.5}$ eta $\mathrm{NO}_{2}$-arekiko esposizioa, hainbat eta T4-maila altuagoa; emaitza estatistikoki esanguratsua $(\beta=0,15, \% 95 \mathrm{KT9}: 0,02 ; 0,27, p=0,019)$ izan da partikulen kasuan eta esangura estatistikotik gertu $(\beta=0,04, \% 95 \mathrm{KT}=:-0,01 ; 0,09, p=0,099)$ egon da nitrogeno dioxidoaren kasuan.

Gako-hitzak: aire-kutsadura, kohorte-ikerketa, fetuaren garapena, haurdunaldia, tiroxina

\section{Abstract}

Thyroid hormones are affected by atmospheric pollution, as it is shown in research papers published in recent years. The aim of this study is to assess the relation between the fine particles (PM2.5) and nitrogen dioxide (NO2) exposure while pregnant, on the heel blood T4 total thyroid hormone of the newborns. For that purpose data from INMA cohort-Gipuzkoa were used. Lineal multivariant models were used to estimate the relation. In our study population of normal healthy pregnancies, PM2.5 exposure during pregnancy was positively associated with higher levels of newborn's heel blood T4levels ( $B=0.15, C 195 \%$ : 0.02; 0.27, $p=0.019)$; the NO2 exposure was positively but marginally significantly associated with heel blood T4-levels ( $6=0.04$, IC95\%: -0.01; 0.09, $p=0.099$ ).

Keywords: air pollution, cohort studies, fetal development, pregnancy, thyroxin

Bidalia: 2018ko urriaren 26an.

Onartua: 2019ko otsailaren 7an.

http://doi.org/10.26876/osagaiz.1.2019.189 


\section{Sarrera}

Osasunaren Mundu Erakundearen arabera, 2016an, 4 milioi pertsona hil zen aire-kutsaduragatik, munduan, eta Europan, berriz, 556.000 pertsona (1). Aire-kutsadura urbanoaren adierazle ontzat ditugu bai $\mathrm{PM}_{2.5}, 2,5$ mikra edo gutxiagoko partikulak, eta bai dioxido nitrogenoa, $\mathrm{NO}_{2}$ eta biek ala biek dute osasunean inpaktu handia. Kontuan izan, $\mathrm{PM}_{2.5}$ oso partikula finak izanik, arnasbideetan erraz sartzen direla. Kutsadurak gizakion osasunean (norberaren osasunean zein osasun kolektiboan) eragiten du, bai zuzen-zuzenean eta bai zeharka, ingurumenean eragiten duelako. Geroz eta ikerketa gehiagok uzten du agerian partikula organiko kutsagarriek zein tabakoaren keak tiroidearen funtzioan eragiten dutela, dela jaioberrietan dela helduetan (2), (3), (4), (5). 2017an argitaratutako lan batean (6), hain justu, suspentsioan dauden 2,5 mikra baino gutxiagoko partikulen eta zilborhesteko hormona tiroideoen arteko asozioazioa aztertu zuten; eta 2018an argitaratu berri den beste batean (7), berriz, bigarren hiruhilekoan $\mathrm{PM}_{2.5}$-en eraginpean egon ziren haurdunen eta haien jaioberrien T4-kontzentrazioen artean erlazio positiboa ikusi dute.

Hormona tiroideoak garrantzitsuak dira gorputzaren funtzionamendu egokirako, arrazoi ugari medio, esate baterako honakoak: nerbio-sisteman eragiten dute; metabolismoa eraentzen dute; bihotztaupaden maiztasuna eta kolesterol-kontzentrazioa kontrolatzen dute, baita, gorputzaren tenperatura eta kaltzio-kopurua ere, odolean; glukogenoaren sintesian eta glukosaren erabilgarritasunean egiten dute lan. Gorputzaren organoen funtzioak kontrolatzeko behar ditugu, finean (8). Baina, gainera, hormona tiroideoak fetuaren garapen optimorako behar-beharrezkoak dira eta, batez ere, fetuaren garapen neurologikorako (9), (10).

Tiroideak elikagaietako iodoa hartzen du. lodoa tirosina deituriko aminoazidoari lotzen zaio eta bi hormona sortzen dira, triyodotironina (T3 ere deiturikoa; metabolikoki aktiboa den hormona) eta tiroxina (T4; zirkulatzen ari den tiroidearen hormona nagusia). T4a T3aren aitzindaria da. Proteina plasmatikoei lotuta (hain zuzen, proteina plasmatikoei lotuta ageri da T4 gehiena, > \% 99 eta TT4 deritzo, T4 totala; gainerakoa T4 librea da, FT4), gorputzera garraiatu eta plazenta zeharkatuta, amaren odoletik fetura iristen da, haurdunaldiaren hasieran (11); hirugarren hiruhilekoan, haurra bere tiroxina sortzeko gai da eta ez da amaren mendeko. Izan ere, haurdunaldiaren bigarren hiruhilekotik aurrera, tiroide-guruinak lan egin dezake eta fetua gai da bere-bereak diren hormonak ekoizteko, amak igarotzen dizkionez gain (12). T4 eta T3 ekoiztu ala ez, hipofisiak edo pituitariak kontrolatzen du, tiroidea estimulatzen duen hormonaren bitartez, alegia, TSHaren bitartez (ingelesez, Thyroid-Stimulating Hormone), zeina, era berean, zirkulatzen ari diren T4- eta T3-kontzentrazioek erregulatzen duten (8). T4 libretik T3 asko eratorri bada organoetan, hipertiroidismoa gerta daiteke eta, aitzitik, ehunek T4 eskasia badute, hipotiroidismoa gerta daiteke.

Erditu eta berehala, jaioberriaren odolean TSH-kontzentrazioa azkar igotzen da; ez, ordea, T4-maila. Haurraren odolean T4-kontzentrazioa gutxitu egin dela antzeman bada, sortzetiko hipotiroidismoa dagoela adieraz (13) dezake, ordea. Euskal Autonomia Erkidegoan, hainbat jaiotzetiko gaixotasunei aurre egiteko, baheketa-programa (14) egiten da, 1982tik, eta bilatzen diren gaixotasun horietako bat da hain zuzen ere, hipotiroidismoa. Kasu horretan, jaioberriaren orpotik ateratako odolaren tiroxina- eta TSH-mailak neurtzen dituzte.

\section{Helburua}

Lan honen helburua da haurdunaldian gertatutako $\mathrm{PM}_{2.5}$-arekiko eta $\mathrm{NO}_{2}$-arekiko esposizioen eta jaioberriaren T4 hormona tiroideo totalaren eta TSHaren arteko asoziazioa aztertzea. 
Gipuzkoako INMA proiektuaren ama-haurren lagina erabili dugu, baita proiektuaren barruan jasotzen dituzten honako datuak ere: atmosferako kutsatzaileak diren $\mathrm{PM}_{2.5}$-ari eta $\mathrm{NO}_{2}$-ari buruzkoak; jaioberrien orpoetatik hartutako TSHari eta T4ari buruzko datuak; erlazioan eragin dezaketen gainerako aldagaiei buruzkoak (koaldagaiak).

\subsection{Populazioa eta lagina}

Guztira, INMA-INfancia y Medio Ambiente (http://www.proyectoinma.org) proiektuan 638 ama-haur bikotek hartu zuten parte. Ikerketan sartzeko irizpideak honakoak izan ziren: kanpoko laguntzarik gabe haurdun gelditzea, haurduna 16 urtez gorakoa izatea eta komunikatzeko arazorik ez izatea. 2006ko maiatzetik 2008ko abuztura bitartean, Zumarragako Ospitalera lehen ekografia egitera zihoazen haurdunak gonbidatu zituzten proiektuan parte hartzera. Gipuzkoako 638 bikoteez gain, Europako beste herrialdeetako partaideek osatzen dute INMA proiektua, eta guztiek protokolo bat dute elkarrekin (15). Parte-hartzaileek baimena eman zuten ikerketan parte hartzeko eta Donostiako Unibertsitate Ospitaleko Etika Batzordeak onartu zuen Gipuzkoako INMA proiektua.

Ikerketa honetarako, aldiz, 467 ama-haur bikote hartu genituen; gaixotasun tiroideorik ez zuten amak hartu genituen kontuan, eta 37 asteko edo gehiagoko haurdunaldiak. Horien guztien hormonei buruzko datuak zein ingurunekoak izan ditugu (1. irudia).

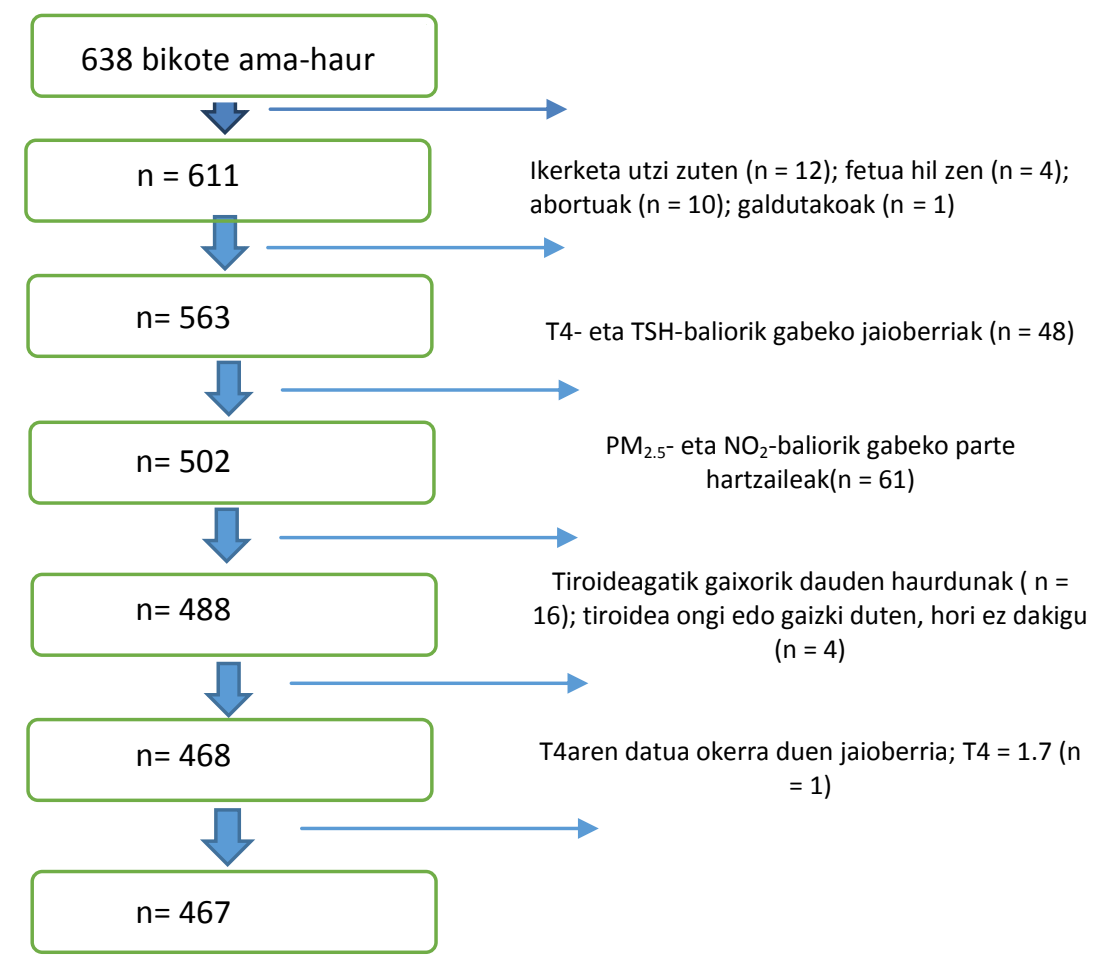

1. irudia. INMA-kohorteko ama-haur bikoteak aukeratzeko irizpideak biltzen dituen fluxu-diagrama.

\subsection{Ikerketa eremua}

Gipuzkoako Lurralde Historikoko $519 \mathrm{~km}^{2}$-ko azalera hartzen du ikerketa eremuak. Honako hiru bailarak hartzen ditu: Goierri-Urola Garaia, Urola Ertaina eta Oria Garaia. 25 herritan banatutako 88.000 biztanle inguru bizi da horietan. Bailarak elkarrekin lotzen dituzten errepideetatik 10.000 eta 40.000 auto inguru igarotzen da egunero. Eremuaren ekonomiaren ezaugarri dira burdinaren eta altzairuaren industriak; 11 konpainia daude Emisio eta Transferentzia Kutsagarrien Euskal Erregistroan (16) (EPER/E-PRTR).

\subsection{Inguruneko ezaugarriak}

\section{a) $\mathrm{PM}_{2.5}$-arekiko esposizioa, jaio aurretik}

Ikerketa hasi zenetik azken erditzeraino, INMA proiektuak $\mathrm{PM}_{2.5}$-maila neurtu zuen egunero, horretarako aerosol-bolumen altuko Digitel DHA-80 neurgailuak erabilita. Bailara bereko bi herritan 
jarri ziren tresnetako bi, eta hilean behin bailara batetik bestera aldatzen ziren. Hirugarren neurgailua Beasainen kokatu zen, Oria Garaian. Modu horretara sei herrialdetako $\mathrm{PM}_{2.5}$-aren denbora-serie ez jarraituak lortu ziren eta herri bakar bateko denbora-serie jarraitua. Edonola ere, aparatuak ez ziren inoiz kutsadurak zuzenki jotzen zien tokietan jarri. Bailara berean, neurgailuak gehienez 3,5 eta $4 \mathrm{~km}$ ra egon ziren. Aipatu tresnek emandako datuez gain, Eusko Jaurlaritzako Airearen Kalitatea Kontrolatzeko Sareak jasotzen dituen datuak hartu genituen kontuan; neurgailu horiek finko daude bailara bakoitzean, eta egunero jasotzen dituzte $\mathrm{PM}_{2.5}$-ari buruzko datuak. Aparatuak bailara batetik bestera aldatzean informazioa galtzen da, eta informazio hori konpentsatzeko inputazio anizkoitzeko (IM) prozedura (17), (18) aplikatu genuen.

Emakume bakoitzari bere herrian kokatutako neurgailuak neurtutako $\mathrm{PM}_{2.5}$-kontzentrazioaren batezbestekoa kalkulatu zitzaion, haurdunaldi osorako; herrian bertan tresnarik ezean, hurbilekoena erabili zen (4 km-ra gehienez).

\section{b) $\mathrm{NO}_{2}$-arekiko esposizioa, jaio aurretik}

$\mathrm{NO}_{2}$-ari buruzko datuak hartzeko, simetria erradiala egiten duten hartzaile pasiboak erabili ziren (Radiello ; Fundazione Salvatore Maugeri, Padua, Italia), ikerketa-eremuan irizpide geografikoak erabiliz kokatuta (19). Hartzaileak toki berean hiru aldiz kokatu ziren, urte berean, eta aldi bakoitzean astebetez neurtu zen $\mathrm{NO}_{2}$-maila. Haurdunaldi osorako, haurdunaren bizitokiaren $\mathrm{NO}_{2}$-maila estimatzeko, Lurraren Erabilerarako Erregresio-ereduak (Land Use Regression, LUR) erabili ziren.

\subsection{TSH eta T4}

Jaio eta 48 ordura, orpotik odola erauzi zitzaien umeei eta iragaz-paperean tantatxo bat jarri, EAEko Jaiotzetiko Gaixotasunen Jaioberrientzako Baheketa Programari jarraiki, eta TSH eta T4 (T4 totala) neurtzeko, hurrenez hurren ondorengo bi kit-ak erabili ziren: kit AutoDELFIA ${ }^{\circledR}$ Neonatal hTSH (B032312 Wallac Oy-k sortua, Mustionkatu 6, Fl-20750 Turku, Finlandia) eta AutoDELFIA T4 Neonatal (AutoDELFIA ${ }^{\circledR}$ Neonatal Thyroxine (T4), B065-112. Wallac Oy-k sortua, Mustionkatu 6, Fl-20750 Turku, Finlandia). Baheketa Programaren azterketak egiteko ardura Osasun Publikoaren Laborategiaren kimika klinikoaren unitateak du eta Egiaztatze Erakunde Nazionalaren (ENAC) onespena du.

Osasun Publikoaren Laborategian, honako balioak erabiltzen dira erreferentziatzat: TSHarentzat 10 $\mu \mathrm{U} / \mathrm{mL}$ eta T4arentzat 6-20 $\mu \mathrm{g} / \mathrm{dL}$, baldin eta $2.500 \mathrm{~g}$ baino gehiago pisatzen badu jaioberriak; hala ez balitz, 5-20 $\mu \mathrm{g} / \mathrm{dL}-k o$ erreferentzia hartuko litzateke, pisu txikientzat.

\subsection{Amaren eta jaioberrien gaineko aldagaiak}

Haurdunaldiaren lehen eta hirugarren hilabeteetan galderak egin zitzaizkien parte-hartzaileei, eta galde-sorta horietatik atera ziren amari eta haurdunaldiari buruzko hainbat datu, hala nola amaren adina, ikasketa-maila (lehen hezkuntza edo gutxiago, bigarren hezkuntza, unibertsitate-ikasketak), etnia (kaukasikoa edo besteren bat), lanbidetik (20) lortutako gizarte-maila (eskuz edo eskuz ez), tabakoarekiko aztura (haurdunaldiko 32. astean erretzen duen edo erretzen jarraitzen ote duen ala ez; esposizio pasiboa), alkohola edateari buruzkoa (amak edaten duen ala ez, eta egitekotan, 0,1g alkohol baino gehiago edo gutxiago hartzen ote duen), zenbat bider erditu den (behin ala gehiagotan) eta iodoa hartzen ote duen haurdunaldian (bai ala ez, lehen bi hiruhilekoetan).

Erregistro klinikotik, berriz, honakoak lortu genituen: jaioberriaren sexua, pisua, jaiotze-astea, Apgar testaren balioak, haurdunaldian amak irabazitako pisua (gomendatutakoa edo hortik gora edo behera duen, honakoaren arabera: Institute of Medicine: Weight Gain During Pregnancy: Reexamining the Guidelines. Washington, National Academy Press, 2009) eta erditze-motari buruzko datuak. Hain zuzen erditze-motari dagozkion datuak, honako 3 kategoriatan sailkatu genituen: aparteko tresnarik behar izan ez zuten erditzeak "eutoziko"tzat hartu genituen; jaiotzerakoan 
tresneria behar izan zuten erditzeak "instrumental" gisa hartu genituen; eta baginatik erditu ezinik, zesareaz atera behar izan ziren haurrak "zesarea" gisa sailkatu ziren. Halaber, jaiotze-asteak lau urtaroetan sailkatu ziren.

\subsection{Analisi estatistikoa}

Lehenik eta behin, lagina deskribatu genuen, amaren aldagai soziodemografikoen eta erditzeari zein jaioberriari lotutako aldagaien arabera. Aldagai mendekoak (T4 eta TSH) eta esposizio-aldagaiak $\left(\mathrm{PM}_{2.5}\right.$ eta $\left.\mathrm{NO}_{2}\right)$ estatistiko deskribatzaileak erabiliz deskribatu genituen. TSH aldagaiak aldakortasunik azaldu ez zuenez, erlazio-azterketa T4arekin bakarrik aztertzea erabaki genuen. T4aren banaketa normala ere aztertu genuen, kurtosia eta asimetria kontrastearen bitartez.

T4-mailak ama eta umeari loturiko aldagaien bitartez ere deskribatu genituen, kontraste parametrikoak erabiliz. Horretarako, kuantitatiboak ziren aldagaiak kategorizatu genituen kontrasterako, irizpide klinikoak edota ebaki-puntu estatistikoak erabiliz. Aldagai dikotomikoetan Student-en $\mathrm{T}$ erabili genuen, eta bi baino gehiagoko kategoriako aldagaietan, berriz, ANOVAren kontrastea.

Bi eredu multibariante eraiki genituen kutsatzaile bakoitzak T4arekin zuen erlazioa ebaluatzeko. Horretarako, eredu multibarianteetan sartu genituen aldagaiek hiru hauetako baldintza bat bete behar zuten: T4arekin erlazioa izatea ( $p$-balioa gehienez 0,10 ); esposizioari loturiko balioa \% 10 aldaraztea; edota guretzat esanguratsua izan ez arren, literaturan garrantzitsutzat jotzea. Eredu multibariantean aukeratutako aldagaiak hauek izan ziren: jaioberriaren pisua, erditze-kopurua eta mota, haurdunaldiaren lehen hiruhilabetekoan iodoa hartzea eta urte-sasoia. Beta koefizienteak eta $\%$ 95eko konfiantza-tarteak erabili genituen, bien arteko erlazioa adierazteko. Statgraphics, Stataren 14. bertsioa (StataCop, CollegeStation, TX, USA) eta SPSSren 23.a erabili genituen kalkuluak egiteko. $\alpha=0,05$ erabili genuen, esangura-muga bezala.

\section{Emaitzak}

Amek, batez beste 31,54 urte zituzten (desbiderapena \pm 3,61 urte; 19-43 [min-max]) eta haurdunaldiaren iraupena, batez beste 39,94 astekoa izan zen (desbiderapena $\pm 1,17$ aste; 37,14 42,57 [min-max]); jaioberriek, batez beste $3.339 \mathrm{~g}$ pisatu zuten (desbiderapena $\pm 432,49 \mathrm{~g}$; 2.090 4.785 [min-max]).

Ama gehienak kaukasikoak ziren (\% 97,6), 25 eta 35 urte bitartekoak (\% 78,2). Erdiek (\% 51) unibertsitatean ikasi zuten eta zertxobait gutxiago (\% 42) gizarte-maila baxukoak ziren (esku-lanetan dabiltzan emakumeak). Amen \% 11,3k erretzen jarraitu zuen azken hiruhilekoan, \% 37,6k alkohola edan zuen, eta iodoa hartu zuen osagarri gisa, bai lehen hiruhilekoan $(\% 87,4)$ eta bai bigarrenean $(\%$ 93,2). \% 38,5k bakarrik mantendu zuen haurdunaldiaren asterako zegokion pisu egokia. \% 14,8 udazkenean erditu zen, eta gehiengoa $(\% 71,3)$ naturalki erditu zen. 1 . taulan ama-haurren aldagaiak deskribatu ditugu.

1 taula. Amen eta jaioberrien ezaugarriak.

\begin{tabular}{lrc}
\multicolumn{1}{c}{ Aldagaiak } & Kategoriak & $\mathbf{n}(\%)$ \\
\hline \multicolumn{1}{c}{ Amaren ezaugarri soziodemografikoak } \\
\\
Amaren adina, haurdunaldiaren & $<25$ & $9(1,9)$ \\
lehen hiruhilekoan & $25-29$ & $140(30)$ \\
& $30-34$ & $225(48,2)$ \\
Amaren adina (urte) & $>35$ & $93(19,9)$ \\
\hline \multirow{2}{*}{ Amaren ikasketa-maila } & & $31,54 \pm 3,61$ \\
& bigarren hezkuntza & $232(51)$ \\
\end{tabular}




\begin{tabular}{|c|c|c|}
\hline & lehen H.ra arte & $57(12,5)$ \\
\hline \multirow{2}{*}{ Amaren etnia } & kaukasikoa & $456(97,6)$ \\
\hline & bestelakoak & $11(2,4)$ \\
\hline \multirow{2}{*}{ Klase soziala (lana) } & eskuz, ez & $271(58)$ \\
\hline & eskuz & $196(42)$ \\
\hline \multicolumn{3}{|c|}{ Ohitura (dieta, alkohola, tabakoa), haurdunaldian } \\
\hline \multirow{3}{*}{ Ama eta alkohola edatea } & ez du edaten & $289(62,4)$ \\
\hline & $\leq 0.1 \mathrm{~g}$ & $100(21,6)$ \\
\hline & $\geq 0.1 \mathrm{~g}$ & $74(16)$ \\
\hline 32. astean, tabakoa erre & $\begin{array}{r}\text { ez du erretzen; } \\
\text { lehenago utzi du } \\
\text { erretzen jarraitzen } \\
\text { du }\end{array}$ & $\begin{array}{l}408(88,7) \\
52(11,3)\end{array}$ \\
\hline \multirow[b]{2}{*}{ Etxean, tabakoarekiko esposizioa } & ez & $392(85,2)$ \\
\hline & bai & $68(14,8)$ \\
\hline \multirow{4}{*}{$\begin{array}{l}\text { Orokorrean, tabakoarekiko } \\
\text { esposizioa }\end{array}$} & esposiziorik ez & $194(42,2)$ \\
\hline & esposizio-iturri 1 & $202(43,9)$ \\
\hline & 2 esposizio-iturri & $59(12,8)$ \\
\hline & 3 esposizio-iturri & $5(1,1)$ \\
\hline \multirow{2}{*}{ lodoa osagarri, lehen hiruhilekoan } & ez & $59(12,6)$ \\
\hline & bai & $408(87,4)$ \\
\hline \multirow{2}{*}{$\begin{array}{l}\text { lodoa osagarri, bigarren } \\
\text { hiruhilekoan }\end{array}$} & $\mathrm{ez}$ & $32(6,9)$ \\
\hline & bai & $435(93,2)$ \\
\hline \multicolumn{3}{|c|}{ Erditzearen eta jaioberriaren ezaugarriak } \\
\hline \multirow{3}{*}{ Haurdunaldian hartutako pisua } & gomendatutakoa & $175(38,5)$ \\
\hline & txikia & $162(35,6)$ \\
\hline & handia & $118(25,9)$ \\
\hline \multirow{3}{*}{ Erditze-mota } & eutozikoa & $333(71,3)$ \\
\hline & tresnak erabiliz & $82(17,6)$ \\
\hline & zesareaz & $52(11,1)$ \\
\hline \multirow[b]{2}{*}{ Aurretiko erditzeak } & lehen erditzea & $242(51,8)$ \\
\hline & $\begin{array}{r}\text { erditze bat baino } \\
\text { gehiago }\end{array}$ & $225(48,2)$ \\
\hline \multirow{4}{*}{ Urtaroa, erditzerakoan } & negua & $142(30,4)$ \\
\hline & udaberria & $140(30)$ \\
\hline & uda & $116(24,8)$ \\
\hline & udazkena & $69(14,8)$ \\
\hline \multirow{2}{*}{ Jaioberriaren sexua } & neska & $233(49,9)$ \\
\hline & mutila & $234(50,1)$ \\
\hline \multirow{2}{*}{ Pisu txikia, jaiotzean $(<2500 \mathrm{~g})$} & ez & $455(97,4)$ \\
\hline & bai & $12(2,6)$ \\
\hline Pisua, jaiotzean (g) & & $3338,65 \pm 432,49$ \\
\hline \multirow[t]{2}{*}{ Fetuaren adina (aste) } & & $39,94 \pm 1,17$ \\
\hline & $\leq 4$ & $1(0,2)$ \\
\hline \multirow[t]{2}{*}{ Apgar-Test, 1. minutuan } & $5-7$ & $20(4,3)$ \\
\hline & $\geq 8$ & $446(95,5)$ \\
\hline
\end{tabular}




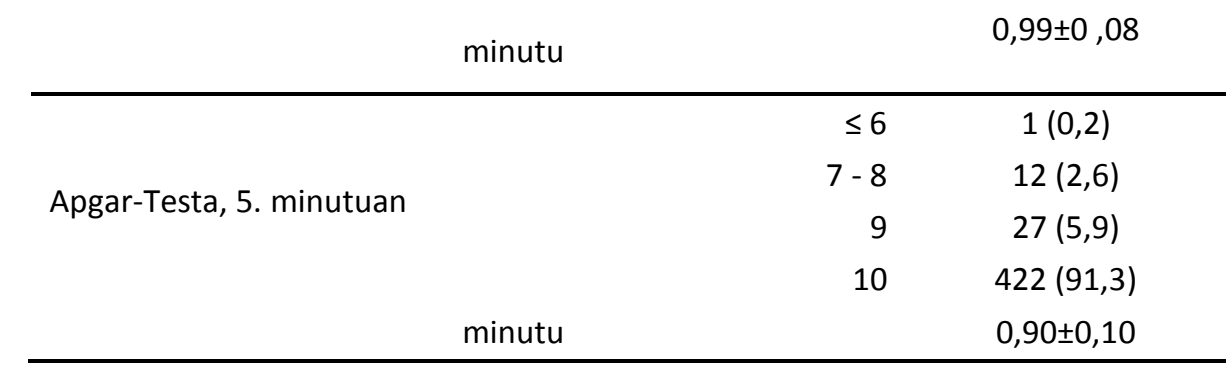

*Kualitatiboak maiztasun absolutu eta portzentaien bitartez; kuantitatiboak batezbestekoaren eta desbiderapen estandarraren bitartez

Jaioberrien \% 49,9 emakumezkoa izan zen; \% 48,2k anai-arrebak zituzten; \% 14,8k kea arnasten zuten etxean, amaren bikotea erretzailea zelako edota etxean jasotzen zituzten ohiko bisitak erretzaileak zirelako. 5 baino gutxiagoko Apgarra haur bakar batek izan zuen, bizitzako lehen minutuan baita 5 . minutuan ere. Hau da, jaioberrien ia guztiek erditzea ongi jasan zuten, nahiz eta \% 17,6k tresnaren bat behar izan zuen erditzeko garaian. Soilik jaioberrien \% 2,6k $2.500 \mathrm{~g}$ baino gutxiago pisatu zuten.

2. taulan eta 2. irudian esposizioari dagozkion aldagaiak deskribatu ditugu.

\section{2. taula. Esposizioari dagozkion aldagaien deskripzioa.}

\begin{tabular}{|c|c|c|c|}
\hline $\begin{array}{c}\text { KUTSATZAILEA } \\
\left(\mu \mathrm{g} / \mathrm{m}^{3}\right)\end{array}$ & Batezbestekoa & $\begin{array}{c}\text { Desbiazio } \\
\text { tipikoa }\end{array}$ & $\begin{array}{c}\text { Heina }(\mathrm{min}- \\
\mathrm{max})\end{array}$ \\
\hline $\mathrm{PM}_{2.5}$ & 16,93 & 2,43 & $10,44-25,65$ \\
\hline $\mathrm{NO}_{2}$ & 18,48 & 6,09 & $6,98-41,93$ \\
\hline
\end{tabular}

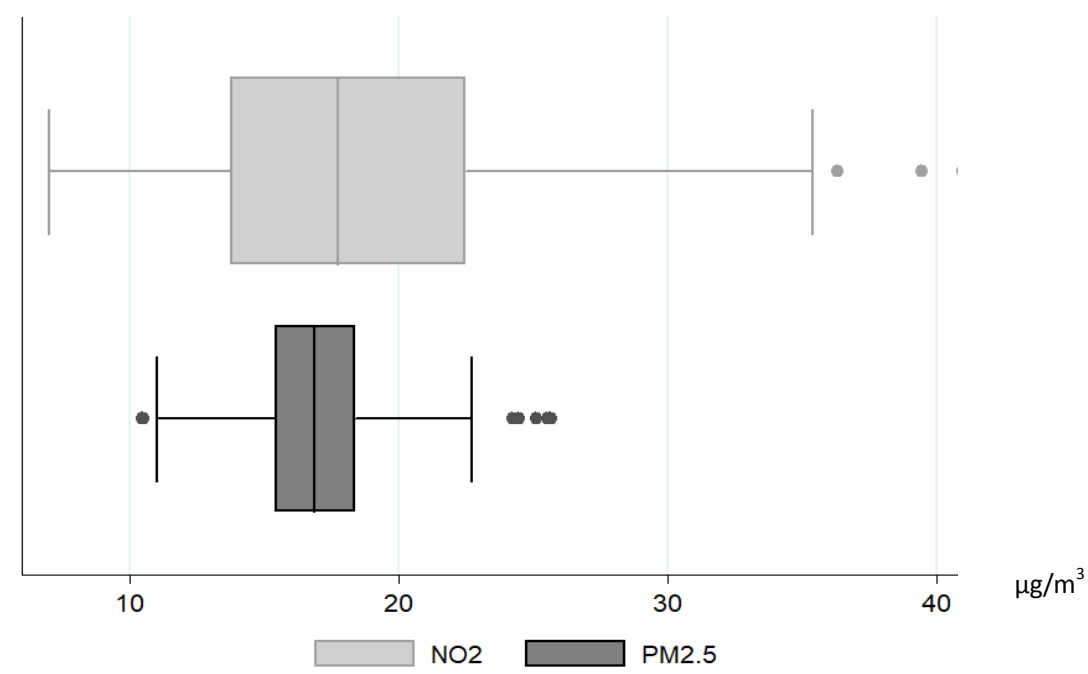

2 irudia $\mathrm{PM}_{2.5}$ eta $\mathrm{NO}_{2}$ kutsatzaileen deskripzioa, grafikoen bitartez.

3. taulan TSH eta T4 hormonak deskribatu ditugu.

3. taula. TSH eta T4 aldagai mendekoen deskripzioa.

\begin{tabular}{|l|c|c|c|}
\hline HORMONA & Batezbestekoa & $\begin{array}{c}\text { Desbiazioa } \\
\text { tipikoa }\end{array}$ & Heina \\
\hline $\mathrm{TSH}(\mu \mathrm{U} / \mathrm{mL})$ & 2,40 & 0,82 & $2-7$ \\
\hline $\mathrm{T} 4(\mu \mathrm{g} / \mathrm{dL})$ & 13,82 & 3,32 & $6,3-19,9$ \\
\hline
\end{tabular}

Ama-haurraren ezaugarriekiko eta esposizioarekiko egindako kontrasteak 4. taulan bildu ditugu. 
4. taula. T4-maila ama-haurren aldagaien arabera.

\begin{tabular}{|c|c|c|c|c|}
\hline Aldagaiak & Kategoriak & batezbestekoa & $\% 95$ KT & p-balioa \\
\hline \multicolumn{5}{|c|}{ Amaren ezagugarri soziodemografikoak } \\
\hline \multirow{4}{*}{$\begin{array}{l}\text { Amaren adina, } \\
\text { haurdunaldiaren lehen } \\
\text { hiruhilekoan }\end{array}$} & $<25$ & 15,86 & $13,04-18,67$ & \multirow{4}{*}{0,316} \\
\hline & $25-29$ & 13,82 & $13,24-14,39$ & \\
\hline & $30-34$ & 13,73 & $13,33-14,14$ & \\
\hline & $>35$ & 13,85 & $13,10-14,61$ & \\
\hline \multirow{3}{*}{ Amaren ikasketa-maila } & unibertsitatea & 13,81 & $13,41-14,21$ & \multirow{3}{*}{0,996} \\
\hline & bigarren hezkuntza & 13,85 & $13,32-14,39$ & \\
\hline & lehen H.ra arte & 13,81 & $12,94-14,67$ & \\
\hline \multirow{2}{*}{ Amaren etnia } & kaukasikoa & 13,82 & $13,51-14,12$ & \multirow{2}{*}{0,759} \\
\hline & bestelakoak & 14,13 & $11,71-16,54$ & \\
\hline \multirow{2}{*}{ Klase soziala (lana) } & eskuz, ez & 13,67 & $13,28-14,05$ & \multirow{2}{*}{0,229} \\
\hline & eskuz & 14,04 & $13,55-14,53$ & \\
\hline \multirow{4}{*}{ Ama eta alkohola edatea } & Ohitura (dieta, alkohola, & bakoa), haurdunald & & \\
\hline & ez du edaten & 13,94 & $13,56-14,33$ & \multirow{3}{*}{0,639} \\
\hline & $\leq 0.1 \mathrm{~g}$ & 13,78 & $13,15-14,40$ & \\
\hline & $\geq 0.1 \mathrm{~g}$ & 13,4 & $12,57-14,22$ & \\
\hline \multirow[t]{2}{*}{ 32. astean, tabakoa erre } & $\begin{array}{l}\text { ez du erretzen; } \\
\text { lehenago utzi du }\end{array}$ & 13,84 & $13,52-14,16$ & \multirow[t]{2}{*}{0,911} \\
\hline & erretzen jarraitzen du & 13,89 & $12,91-14,88$ & \\
\hline \multirow{2}{*}{$\begin{array}{l}\text { Etxean, tabakoarekiko } \\
\text { esposizioa }\end{array}$} & ez & 13,79 & $13,47-14,12$ & \multirow{2}{*}{0,424} \\
\hline & bai & 14,14 & $13,28-15,01$ & \\
\hline \multirow{4}{*}{$\begin{array}{l}\text { Orokorrean, } \\
\text { tabakoarekiko esposizioa }\end{array}$} & esposiziorik ez & 13,71 & $13,25-14,17$ & \multirow{4}{*}{0,608} \\
\hline & esposizio-iturri 1 & 13,85 & $13,40-14,31$ & \\
\hline & 2 esposizio-iturri & 14,22 & $13,31-15,23$ & \\
\hline & 3 esposizio-iturri & 13,86 & $10,03-17,70$ & \\
\hline \multirow{2}{*}{$\begin{array}{l}\text { lodoa osagarri, lehen } \\
\text { hiruhilekoan }\end{array}$} & ez & 14,57 & $13,73-15,41$ & \multirow{2}{*}{0,064} \\
\hline & bai & 13,71 & $13,39-14,04$ & \\
\hline \multirow[b]{2}{*}{$\begin{array}{l}\text { lodoa osagarri, bigarren } \\
\text { hiruhilekoan }\end{array}$} & ez & 14,19 & $12,83-15,55$ & \multirow[b]{2}{*}{0,517} \\
\hline & bai & 13,8 & $13,49-14,11$ & \\
\hline \multicolumn{5}{|c|}{ Erditzearen eta jaioberriaren ezaugarriak } \\
\hline \multirow{3}{*}{$\begin{array}{l}\text { Haurdunaldian hartutako } \\
\text { pisua }\end{array}$} & gomendatutakoa & 13,67 & $13,18-14,16$ & \multirow{3}{*}{0,227} \\
\hline & txikia & 14,03 & $13,53-14,53$ & \\
\hline & handia & 13,94 & $13,29-14,59$ & \\
\hline \multirow{3}{*}{ Erditze-mota } & eutozikoa & 13,53 & $13,17-13,89$ & \multirow{3}{*}{0,003} \\
\hline & tresna erabiliz & 14,92 & $14,23-15,61$ & \\
\hline & zesareaz & 13,96 & $13,02-14,90$ & \\
\hline & lehen erditzea & 14,1 & $13,70-14,50$ & \\
\hline Aurretiko erditzeak & $\begin{array}{r}\text { erditze bat baino } \\
\text { gehiago }\end{array}$ & 13,52 & $13,07-13,98$ & 0,061 \\
\hline & negua & 14,75 & $14,20-15,30$ & \\
\hline Urtaroa, erditzerakoan & udaberria & 13,08 & $12,55-13,61$ & $<0,001$ \\
\hline & uda & 13,57 & $13,00-14,15$ & \\
\hline
\end{tabular}




\begin{tabular}{|c|c|c|c|c|}
\hline & udazkena & 13,85 & $12,98-14,72$ & \\
\hline \multirow{2}{*}{ Jaioberriaren sexua } & neska & 13,84 & $13,42-14,26$ & \multirow{2}{*}{0,9} \\
\hline & mutila & 13,8 & $13,37-14,24$ & \\
\hline \multirow{2}{*}{$\begin{array}{l}\text { Pisu txikia, jaiotzean } \\
(<2500 \mathrm{~g})\end{array}$} & ez & 13,85 & $13,55-14,16$ & \multirow{2}{*}{0,203} \\
\hline & bai & 12,62 & $10,28-14,96$ & \\
\hline \multirow{3}{*}{ Apgar test, 1 . minutuan } & $\leq 4$ & 8,5 & _ & \multirow{3}{*}{0,272} \\
\hline & $5-7$ & 13,70 & $12,04-15,35$ & \\
\hline & $\geq 8$ & 13,84 & $13,53-14,15$ & \\
\hline \multirow{4}{*}{ Apgar testa, 5. minutuan } & $\leq 6$ & 12,3 & _- & \multirow{4}{*}{0,715} \\
\hline & $7-8$ & 14,46 & $12,34-16,57$ & \\
\hline & 9 & 14,56 & $13,10-16,01$ & \\
\hline & 10 & 13,76 & $14,44-14,0$ & \\
\hline \multicolumn{5}{|c|}{ Esposizioa } \\
\hline \multirow{2}{*}{$\mathrm{PM}_{2.5}(\mu \mathrm{g} / \mathrm{m} 3)$} & $<=16,70$ & 13,35 & $12,94-13,76$ & \multirow{2}{*}{0,001} \\
\hline & $>16,70$ & 14,33 & $13,89-14,77$ & \\
\hline \multirow{2}{*}{$\mathrm{NO}_{2}(\mu \mathrm{g} / \mathrm{m} 3)$} & $<=18,48$ & 13,67 & $13,26-14,09$ & \multirow{2}{*}{0,281} \\
\hline & $>18,48$ & 14,01 & $13,56-14,45$ & \\
\hline
\end{tabular}

KT konfiantza-tartea da; PM2.5, 2,5 mikra edo gutxiagoko partikulak; NO2, nitrogeno dioxidoa.

Neguan, lehen aldiz erditzeak, haurdunaldiaren lehen hiruhilekoan iodorik ez hartzeak, jaiotzeko tresnaren bat behar izateak eta haurdunaldian $\mathrm{PM}_{2.5}$ kutsatzaileekiko esposizioan egon izanak jaioberriaren T4-maila handitzen dute. 5. taulan azaldu dugu T4 aldagai mendekoak $\mathrm{PM}_{2.5}$ eta $\mathrm{NO}_{2}$ esposizioaren aldagaiekin duen erlazioa.

\section{5. taula. T4 hormonaren erregresio-eredu lineal multibariantea, $\mathrm{PM}_{2.5}$-aren eta $\mathrm{NO}_{2}$-aren arabera.}

\begin{tabular}{|c|c|c|c|c|c|c|}
\cline { 2 - 7 } \multicolumn{1}{c|}{} & \multicolumn{3}{c|}{ Datu gordinak } & \multicolumn{3}{c|}{ Doitutako datuak } \\
\cline { 2 - 7 } \multicolumn{1}{c|}{${ }^{$\cline { 2 - 6 }$}$} & $\beta_{0}$ & $\begin{array}{c}\text { Konfiantza- } \\
\text { tartea \% 95 }\end{array}$ & p-balioa & $\beta_{0}{ }^{*}$ & $\begin{array}{c}\text { Konfiantza- } \\
\text { tartea \% 95 }\end{array}$ & p-balioa \\
\hline $\mathrm{PM}_{2.5}$ & 0,23 & $0,11-0,36$ & $<0,001$ & 0,15 & $0,02-0,27$ & 0,019 \\
\hline $\mathrm{NO}_{2}$ & 0,03 & $-0,02-0,02$ & 0,202 & 0,04 & $-0,01-0,09$ & 0,099 \\
\hline
\end{tabular}

*Honakoengatik doituta: urtaroa, jaioberriaren pisua, haurdunaldiko lehen hiruhilekoan iodoa hartzea, aurretik izandako erditzeak, erditze-mota.

Ereduak agertu duenez, metro kubikoko $\mathrm{PM}_{2.5}$ mikrogramo bat handitzean, dezilitroko, batez beste 0,15 mikrogramo handituko da tiroxina-maila ( $p$-balioa=0,019). Erlazioa positiboa da baita ere $\mathrm{NO}_{2-}$ aren eta T4aren artean, baina erlazio hori estatistikoki mugan geratzen da ( $p$-balioa=0,099).

\section{Eztabaida}

Lan hau, aipatu helburua duen lehen azterketa epidemiologikoa da, Euskal Herrian, oraingoz, bakarra. INMA proiektuari esker, ehunka laguneko lagina dugu $(n=467)$ eta haiei buruzko informazio andana; horiek lagungarri dira aldagaien arteko benetako erlazioa aztertzeko.

Ikerketa honetan ikusi dugunez, haurdunaldian $\mathrm{PM}_{2.5}$-aren eraginpean egoteak jaioberriaren $\mathrm{T} 4$ totalaren mailan eragina du. Beste bi ikerketak aztertu dute haurdunaren partikulekiko esposizioaren eta jaioberrien tiroidearen funtzionamenduaren arteko erlazioa; Janssenek eta taldekideek 2017an egindakoak (6), eta Howe CGk eta taldekideek berriki egindakoak (7), 2018an. 
Janssen et al.-ek proposatu dute $\mathrm{PM}_{2.5}$ partikulek areagotu egiten dutela T4 T3 bilakatzea, 2deiodinasaren aktibitatea induzituz; era berean, $\mathrm{PM}_{2.5}$-aren eta $\mathrm{T} 4$ librearen artean alderantzizko erlazioa aurkitu zuten. Bestalde, gure emaitzek bezala, Howe CGk eta taldekideek haurdunaren $\mathrm{PM}_{2.5}$-ekiko esposizioa jaioberriaren T4-kontzentrazio altuekin erlazionatuta dagoela iradoki dute, eta haratago joan dira haurdunaldiaren zein astetako esposizioak duen eragina aztertuta.

Bestalde, beste hainbat lanetan bezala (6), (9), neguak jaioberriaren tiroxina-maila alda dezakeela agertu zaigu lan honetan. Neguan jaio ez direnek batezbeste $1,25 \mu \mathrm{g} / \mathrm{dL}$ gutxiago dute neguan jaio direnek baino. Hala eta guztiz ere, ezin dugu esan negua denik T4-maila igotzeko arrazoia, hain zuzen ere neguan atmosferako partikula-maila igo ohi delako, bai inbertsio termikoarengatik bai industria aktiboagoa delako neguan, udan baino.

Tresnaz lagundutako erditzeak estres handiagoa sor diezaioke jaioberriari naturalki jaiotzeak baino, eta ikerketa honetan ikusi dugunez, horrek tiroxina-mailarekin badu erlaziorik. Orain baino lehen, beste ikerketa batzuetan ikusi izan dute jaiotzean sortutako estresak hormona tiroideoak asaldu ditzakeela (24), (25) eta TSH-maila igo dezaketela (25), (26). Bestalde, bai Trumph eta kideek ${ }^{9}$ eta bai Linding Andersenen taldeak (23) lehen hiruhilekoan iodoa osagarritzat hartzeak jaioberriaren TSHmaila igoarazten duela ondorioztatzen dute. Gure lanean ikusi dugunez, iodorik ez hartzeak tiroxinamaila altuagoa sor dezake. Ikerketa gehiago argitaratu ahala, interesgarria izango da jaiotzeak sortzen duen estresak zein amak iodoa hartzeak edo ez hartzeak tiroxina-mailarekin erlaziorik duenetz ikustea.

Haurdunaldian gomendatutako pisutik gora edo behera egoteak tiroxina-maila igotzen dio jaioberriari (9) eta lehen aldiz erditzen diren emakumeen haurren tiroxina-maila altuagoa izan liteke (batez beste 14, 10) aurretik erditu diren horien umeena (batez beste, 13,52) baino. Emaitza horiek bat egiten dute bibliografian aurki daitekeenarekin (22), (24), (25). Aitzitik, beste batzuetan ez bezala, gure ikerketan ez dugu ikusi haurdunaldian alkohola (23) edateak, tabakoa erretzeak (5), (9), (27) ezta zigarrokinen kea arnasteak (5), (6), (27) ere jaioberrien T4-mailarekin erlaziorik dutenik.

Tiroxina-mailan aldaketak espero ditugula ikusi dugu, honakoak gertatzean: amaren lehen erditzea denean; tresnaz lagunduriko erditzea denean; haurdunaldiaren lehen hiruhilekoan iodoa osagarritzat hartzen ez duenean; urtaroan, neguan igo egiten baita; haurdunaldian, $\mathrm{PM}_{2.5}$ partikulen eraginpean egotea. Interesgarritzat jotzen dugu tiroidea eta iodoa aztertuko dituzten ikerketetan $\mathrm{PM}_{2.5}$ eta $\mathrm{NO}_{2}$ aldagaiak kontuan hartzea. Kontuan izan, Europan tiroidearen funtzioa aztertzeko TSH (28) erabiltzen dugun moduan, Ipar Ameriketan T4 erabiltzen dute, Tiroidearen Ameriketako Erakundearen arabera.

Janssenek eta kideek diotenez, T3 eta T4 libreek erregulatzen dute zelulen funtzionamendua (29). T4 eta T3 hormonak TBG (tiroxina fixatzen duen globulina, ingelesezko hitzetatik eratorria) deitzen den proteina bati lotzen zaizkio, eta, ondorioz, organu eta ehunek ezin dituzte hormona horiek erabili. Odolean dabilen T4aren eta T3aren \% 99 baino gehiago lotuta agertzen da. Hortaz, \% 1 edo \% 2 osatzen duten T4 eta T3 askeak dira soilik kimikoki aktiboak, eta soilik horiek sar daitezke zeluletan eta modula dezakete gorputzaren metabolismoa (8). Organoetan eta ehunetan, soilik T4 librea bilaka daitekeenez T3, tiroidearen guruineko ikerketetan (24), (30) huraxe erabili izan da. Janssenek eta kideek halaxe egin zuten, suspentsioan dauden partikulen eta zilbor-hesteko hormona tiroideoen arteko asoziazioa aztertu zutenean (6). Aitzitik, guk T4 totala erabili dugu, Howek eta kideek bezalaxe (7), librea erabili beharrean. Kontuan hartu behar da hori, lan hau beste ikerketa batzuekin alderatu nahi dugunean.

Esposizioaren eta efektuaren arteko erlazioa esanguratsua dela atera zaigu lan honetan, eta aldagai nahasle ugari kontuan hartu baditugu ere, gerta daiteke erlazio hori nahas dezakeen besteren bat egotea. Gurea baino lagin handiagoak sendotasuna emango lioke emaitzari. Ikerketa-lerro honetan lan egiten jarraitu behar dugu, hortaz, emaitzei sendotasuna emateko, datu gehiago lortuz eta mekanismo fisiologikoak ulertuz. 


\section{Ondorioak}

Estatistikoki esanguratsua den erlazio positiboa aurkitu dugu haurdunak $\mathrm{PM}_{2.5}$ partikulen eragina jasatearen eta jaioberriaren tiroidearen T4 (tiroxina) hormona-mailaren artean, eta erlazio horretan honakoek eragin dute: amaren lehen erditzea izateak, erditzea instrumentala izateak, haurdunaldiaren lehen hiruhilekoan iodorik ez hartzeak, neguan erditzeak. Horiek T4-maila igo dezakete. Hala ere, emaitza hauek sendotze aldera, ikerketa epidemiologiko gehiago behar direla uste dugu.

\section{Interes-gatazka}

Ez dugu.

\section{Oharrak eta finantzaketa}

Lan hau EHUko Osasun Publikoko master amaierako lanetik eratorria da.

Ikerketa hau INMA (INfancia y Medio Ambiente) proiektuaren parte da, honakoen diru-laguntza jaso duena: Instituto de Salud Carlos III (PI06/0867), Eusko Jaurlaritzako Osasun Saila (2005111093), Gipuzkoako Foru Aldundia (DFG06/002) eta ikerketa-eremuko udalak (Zumarraga, Urretxu, Legazpi, Azkoitia, Azpeitia eta Beasain).

\section{Erreferentzia bibliografikoak}

1. Eskuragarri: $\quad$ http://www.euro.who.int/en/health-topics/environment-and-health/airquality/news/news/2018/5/over-half-a-million-premature-deaths-annually-in-the-europeanregion-attributable-to-household-and-ambient-air-pollution

2. Pedersen M, Stayner L, Slama R, Sorensen M, Figueras F, Nieuwenhuijsen MJ, RaaschouNielsen O, Dadvand P. Ambient air pollution and pregnancy-induced hypertensive disorders. Hypertension. 2014; 64(3): 494-500.

3. Sawicka-Gutaj N, Gutaj P, Sowiński J, Wender-Ożegowska E, Czarnywojtek A, Brązert J, Ruchała M. Influence of cigarette smoking on thyroid gland-an update. Endokrynol Pol. 2014; 65(1): 54-62.

4. Abdelouahab N, Langlois MF, Lavoie L, Corbin F, Pasquier JC, Takser L. Maternal and cordblood thyroid hormone levels and exposure to polybrominated diphenyl ethers and polychlorinated biphenyls during early pregnancy. Am J Epidemiol. 2013; 178(5):701-713.

5. Czarnywojtek A, Warmuz-Stangierska I, Zdanowska J, Florek E, Zgorzlewicz M, Ruchała M, Stangierski A, Sowiński J. Smoking and thyroid disease-review of literature. Przegl Lek. 2009;66(10):878-81.

6. Janssen BG, Saenen ND, Roels HA, Madhloum N, Gyselaers W, Lefebvre W, Penders J, Vanpoucke^I C, Vrijens K, Nawrot TS. Fetal thyroid function, birth weight, and in Utero exposure to fine particle air pollution: a birth cohort study [Internet]. Environ Health Perspect. $2017 \quad$ [Kontsulta :2018-11-05]; 125(4):699-705. Eskuragarri: https://www.scopus.com/inward/record.uri?eid=2-s2.085009862883\&doi=10.1289\%2FEHP508\&partnerID=40\&md5=6021d6444299b3bb0e7d6325 57a4bce1.

7. Howe CG, Eckel SP, Habre R, Girguis MS, Gao L, Lurmann FW. Association of prenatal exposure to ambient and traffic-related air pollution with newborn thyroid function. JAMA Network Open. 2018;1(5):e182172. 
8. aecat: asociación española de cáncer de tiroides [Internet]. Madrid: Asociación Española de Cáncer de Tiroides, c2012 [Kontsulta: 2018-10-09]. Eskuragarri: http://www.aecat.net/elcancer-de-tiroides/la-glandula-tiroides/funcion/

9. Trumpff C, Vandevijvere S, Moreno-Reyes R, Vanderpas J, Tafforeau J, Van Oyen H, De Schepper J. Neonatal thyroid-stimulating hormone level is influenced by neonatal, maternal, and pregnancy factors. Nutr Res. 2015; 35(11): 975-981.

10. Patel J, Landers K, Li H, H.Mortimer R, Richard K. Delivery of maternal thyroid hormones to the fetus Trends Endocrinol Metab. 2011; 22(5):164-170.

11. Calvo RM, Jauniaux E, Gulbis B, Asunción M, Gervy C, Contempré B, Morreale de Escobar G. Fetal tissues are exposed to biologically relevant free thyroxine concentrations during early phases of development. J Clin Endocrinol Metab. 2002; 87(4):1768-1777.

12. Morreale de Escobar G, Obegon MJ, Escobar del Rey F. Role of thyroid hormone during early brain development. Eur J Endocrinol. 2004; 151(suppl3):U25-U37.

13. Perkin Elmer Wallac AutoDELFIA 1235 Automatic Immunoassay System. T4 neonatal. Guía de uso 2010.

14. Programa de cribado neonatal de enfermedades congénitas de la CAPV: memoria año 2014 [Internet]. Vitoria-Gasteiz: Osakidetza. Euskal Osasun Zerbitzua= Servicio Vasco de Salud; Eusko Jaurlaritza. Osasun Saila=Gobierno Vasco. Departamento de Salud; 2014 [Kontsulta: 2018-11-05] 18 or. Eskuragarri: https://www.osakidetza.euskadi.eus/informacion/pruebadel-talon/r85-cksalu04/es/adjuntos/Memoria 2014.pdf.

15. Guxens $M$, Aguilera I, Ballester F, Estarlich $M$, Fernández-Somoano A, Lertxundi $A$, Lertxundi $\mathrm{N}$, Mendez MI, Tardón A, Vrijheid M, Sunyer J, INMA (INfancia y Medio Ambiente) Project. Prenatal exposure to residential air pollution and infant mental development: Modulation by antioxidants and detoxification factors. Environ Health Perspect [Internet]. 2012 [Kontsulta: 2018-11-05];120(1):144-149.

Eskuragarri: https://www.ncbi.nlm.nih.gov/pmc/articles/PMC3261939/pdf/ehp.1103469.pdf

16. Registro Estatal de Emisiones y Fuentes Contaminantes (PRTR) [Internet]. Madrid: Gobierno de España. Ministerio para la transición ecológica [Kontsulta: 2018-11-05] 2006. Eskuragarri: http://www.prtr-es.es/

17. Li F, Baccini M, Mealli F, Zell F, Frangakis CE, Rubin DB. Multiple imputation by ordered monotone blocks with application to the anthrax vaccine research program. J Comput Graph Stat. 2014; 23(3):877-892.

18. Lertxundi A, Baccini M, Lertxundi N, Fano E, Aranbarri A, Martínez MD, Averdi M, Álvarez J, Santa-Marina L, Dorronsoro M, Ibarluzea. Exposure to fine particle matter, nitrogen dioxide and benzene during pregnancy and cognitive and psychomotor developments in children at 15 months of age. Env International. 2015; 80:33-40.

19. Estarlich M, Ballester F, Aguilera I, Fernández-Somoano A, Lertxundi A, Llop S, Freire C, Tardón A, Basterrechea $M$, Sunver J, Iñiquez $C$. Residential exposure to outdoor air pollution during pregnancy and anthropometric measures at birth in a multicenter cohort in Spain. Environ Health Perspect. 2011 Sep; 119(9):1333-1338

20. Wechsler D, Kaufman A, Lichtenberger E. WAIS-III: escala de inteligencia de Wechsler para 
adultos-III: manual técnico. Madrid: TEA, 2001. $252 \mathrm{p}$

21. Mahmood Dhahir Al-Mendalawi. Neonatal thyroid screening: relationship between cord blood thyroid stimulating hormone levels and thyroid stimulating hormone in heel prick sample on 4th to 7th day-of-life. Indian J Endocrinol Metab. 2015; 19(1):188-189.

22. Lee SY. Perinatal factors associated with neonatal thyroid-stimulating hormone in normal newborns [Internet]. Ann Pediatr Endocrinol Metab. 2016 [Kontsulta: 2018-11-05]; 21(4):206. $\quad$ Eskuragarri: apem.org/journal/view.php?doi=10.6065/apem.2016.21.4.206.

23. Andersen SL, Olsen J, Laurberg P. Maternal thyroid disease in the Danish National Birth Cohort: prevalence and risk factors. European Journal of Endocrinology. 2016; 174: 203-212.

24. Korevaar TIM, Chaker L, Jaddoe VWV, Visser TJ, Medici M, Peeters RP. Maternal and birth characteristics are determinants of offspring thyroid function. J Clin Endocrinol Metab. 2016;101(1):206-213.

25. Lakshminarayana SG, Sadanandan NP, Mehaboob AK, Lakshminarayana RG. Effect of maternal and neonatal factors on cord blodd thyroid stimulating hormone. Indin J Endocrinol Metab. 2016; 20(3):317-323.

26. Sak E, Akin M, Aktürk Z, Akin F, Atay E, Aydoğdu C, Yüzkollar E. Investigation of the relationship between low Apgar scores and early neonatal thyroid function. Pediatr Int. 2000; 42(5): 514-516.

27. Sawicka-Gutaj N, Gutaj P, Sowinski J, Wender-Ozegowska E, Czarnywojtek A, Brqzert J, Ruchata M. Influence of cigarette smoking on thyroid gland-an update. Endocrynol Pol. 2014; 65(1): 54-62.

28. Arrizabalaga JJ, Jalón M, Espada M, Cañas M, Arena JM, Vila L. Estado de nutrición de yodo y prevalencia de concentraciones anormales de TSH en la población escolar de 6-7 años de la comunidad autónoma del País Vasco. Endocrinol Diabetes Nutr. 2018; 65(5): 247-254.

29. Hennemann G, Docter R, Friesema ECH, de JOng M, Krenning EP, VIsser TJ. Plasma membrane trasport of thyroid hormones and its role in thyroid hormone metabolism and bioavailability. Endocr Rev. 2001;22(4):451-476.

30. Khalid AS, Marchocki Z, Hayes K, Lutomski JE, Joyce C, Stapleton M, O'Mullane J, O'Donoghue K. Establishing trimester-specific maternal thyroid function reference intevals. Ann Clin Biochem. 2014;51(2):277-283. 
Arantxa Txintxurreta Agirre, Aitana Lertxundi Manterola, Amaia Irizar Loibide, Maria Dolores 